\title{
Research on the Development Model of Characteristic Towns
}

\author{
Yi Wenfang \\ School of Architecture and Engineering \\ Guangzhou Nanyang Institute of Technology \\ Guangzhou, China \\ Ywf1235200@163.com
}

\begin{abstract}
Characteristic towns are an important measure to implement the goal of new-type urbanization under the new normal economic situation, and a nationwide upsurge of building new towns has arisen. Based on the difference between Zhejiang and the Ministry of Residence and Construction in defining characteristic towns, this paper puts forward the "platform model" and "constructed town model" for the development of characteristic towns, and reveals the difference and relationship between the "dual" model from six aspects: background, theoretical basis, concept, essence, goal and function. Because of the different construction bases of different regions in China, the paper puts forward the ge ne ral planning suggestions of classified guidance and diversified development as well as the Enlightenment of the construction that the planning of characteristic towns is more important than the planning, the industry is more important than the location, the method is more important than the fund, and the survival is more important than the policy to provide theoretical support and ideas for the establishment and long-term construction of small towns with future characteristics, and strive to implement the practice of China's new urbanization construction, to promote social and economic transformation and upgrading.
\end{abstract}

Keywords-characteristic town; platform mode; construction mode

\section{INTRODUCTION}

In order to adapt to and guide the new normal economic situation, and to implement the important instructions given by the leaders of the state to Zhejiang Province to "do things without end and go ahead to seek a new chapter", the Zhejiang provincial government took the lead in exploring the new mode of Characteristic Towns in the whole country in June 2015; state leaders fully affirmed Zhejiang's practice and made important instructions in the 'Investigation Report on Small Towns with Zhejiang Characteristics", emphasizing that it is of great significance to pay attention to the construction of small towns and towns with special characteristics and to the economic transformation and upgrading and the construction of new urbanization in December 2015; in July 2016, the Ministry of Housing and Urban-Rural Development and Reform, the State Development and Reform Commission and the Ministry of Finance jointly issued a paper to implement the spirit of the Party and the State Council on promoting the construction of small towns and towns with distinctive features, deciding to

Fund Project: Youth Innovation Project of Guangdong Provincial Education Department Study on Characteristic Town Planning from the Perspective of Smart Village-Taking Conghua District of Guangzhou as an Example (2017GWQNCX083) carry out the cultivation of small towns with distinctive characteristics nationwide, and proposes to cultivate 1000 small towns with distinctive characteristics, suitable for Industry and livable by 2020; subsequently, in October 2016 and August 2017, the Ministry of Housing and Construction published two batches of 403 (the first batch of 127; the second batch of 276) lists of towns with Chinese characteristics. So far, this kind of development pattern, which originated in Zhejiang Province and characterized by regional spatial reconstruction and growth factor agglomeration, has emerged from the sky and swept across the Yangtze River rapidly.

According to the Zhejiang Provincial People's Government's Guiding Opinions on speeding up the planning and construction of characteristic town: "characteristic town is a development space platform which is relatively independent of urban areas and has a clear industrial orientation, cultural connotation, tourism and certain community functions, and is different from administrative division units and industrial parks Throughout the list of China's Characteristic Towns published by the Ministry of Housing and Construction, combined with the notice of the three ministries and commissions on the cultivation of characteristic towns, characteristic towns are in principle constructed towns (except County towns), giving priority to the selection of key towns in the country"; According to the guidance of the State Development and Reform Commission on speeding up the construction of small towns with beautiful features, this paper puts forward that small towns with special features include two forms: characteristic towns and small towns. Characteristic town is a platform for innovation and entrepreneurship different from administrative town and industrial park. Small towns with beautiful features refer to the traditional administrative divisions as a unit. Characteristic towns and small towns complement each other and support each other, that is, the National Development and Reform Commission has clearly separated "characteristic town" from "small towns with beautiful features".

According to the policy analysis, there is a "dual model" in the construction of China's characteristic town: one is the "platform model" which emphasizes positioning the "platform" of industry, promotes industrial transformation and upgrading, and strives to create regional economic growth poles. ${ }^{[1]}$; the other is to promote the construction of a new type of urbanization, emphasizing the role of urbanization in rural construction radiation-driven "town-building model". Although 
the "platform model" has the successful experience of Zhejiang Province for reference, but the basis and regional conditions of different regions in China are different, Zhejiang's construction model and experience can not be replicated throughout the country ${ }^{[2]}$; "town-building model" is still in the exploration. At present, the construction of characteristic town has set off a nationwide upsurge, but at the same time confusion. Therefore, to explore the development model of characteristic town is of great significance to promote the healthy development of characteristic town.
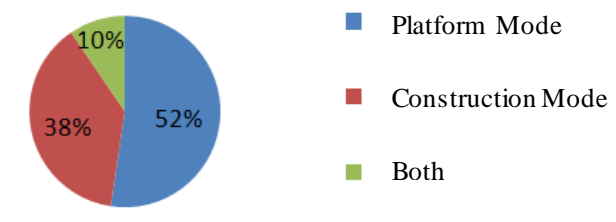

Note: The data comes from the administrative offices of the people's governments of 21 provinces, municipalities and autonomous regions.

Fig. 1. Statistical table of the construction model of characteristic towns

\section{Characteristic Town Development "Dual Mode" DIFFERENCE}

\section{A. Presenting background}

\section{1) The Background of "Platform Mode"}

Characteristic town is inspired by foreign countries such as Davos in Switzerland, Greenwich Hedge Fund in the United States and Provence in France. These towns have unique industrial orientation, and attract tourists from all over the world because of their unique culture and tourism resources, thus achieving regional economic prosperity. Looking from the historical origin, China's characteristic town originated from the practice of Zhejiang "block economy" and regional characteristic industries for many years. Zhejiang is one of the most developed provinces in China's market economy. In the past 30 years, tens of thousands of small and medium-sized enterprises in Zhejiang have formed nearly 500 industrial clusters with an output value of more than 500 million yuan ${ }^{[3]}$. "Block economy" is the main form of industrialization in Zhejiang Province. It plays an important role in the process of rapid economic take-off, expansion and strengthening, and still occupies an important position. However, Zhejiang's 'lump economy" has also exposed problems such as homogenization of industries, weak innovation capability, insufficient follow-up power and effective supply. Under the adjustment of world industrial structure and the new normal of China's economy, Zhejiang hopes to re-optimize the distribution of productive forces through the construction of characteristic town, break the bottleneck of space resources and effective supply shortage, low high-end factor polymerization degree and other issues ${ }^{2}[$.

\section{2) The Background of the "Formal Town Model"}

From the development stage of urbanization, China's urbanization has experienced a period of 1.0 in which resources, elements and industries converge to cities and towns; the urban diseases such as the increasing number, scale, population expansion, serious pollution, traffic congestion and so on are highlighted in the 2.0 era; in 2016, China's urbanization rate reached $57.4 \%$ and urbanization is entering a
3.0 era when resources, factors and industries are spreading outward and the mode of urban development has changed from "urbanization" to 'big City + characteristic town". Therefore, characteristic town has become an important carrier for the transfer of functions in the urbanization $3.0^{[5]}$. From the perspective of the national urbanization development strategy, the report of the 19th National Congress of the CPC puts forward that the urban agglomeration should be the main body and the urban pattern of the coordinated development of large, medium and small cities and towns should be constructed. The development of small towns and characteristic towns undoubtedly plays an extremely important role. The State Council's opinions on deepening the construction of new-type urbanization also make it clear that we should speed up the development of characteristic towns, promote the integration of small towns and evacuating the functions of the central urban areas of large cities, and promote agricultural modernization and urbanization of farmers in the vicinity. The guiding ideology of the "established town model" is to promote the new urbanization and beautiful rural construction by relying on the development of cultural town, so as to promote the coordinated urban development of large, medium and small cities and small towns.

\section{B. Theoretical Basis}

1) The Theoretical Basis of the "Platform Model".

Industrial agglomeration is a dynamic process in which the same industry is highly concentrated in a particular region and the elements of industrial capital are continuously agglomerated in the space. The study of industrial agglomeration began at the end of the 19th century. Marshall paid attention to the economic phenomenon of industrial agglomeration and put forward the concepts of "internal economy" and "external economy". There are two types of industrial agglomeration, namely, the market creation model and the capital transfer model: the market creation model first appears in a specialized market in a specific region. With the continuous improvement of market trading conditions and information conditions, an industrial cluster with complete industrial chains is finally formed. The industrial agglomeration in Zhejiang Province is a typical example of this type. Capital transfer mode generally occurs in the context of industrial transfer, the formation of this industrial agglomeration, mainly through a certain amount of capital from the outside to move in, causing similar enterprises to converge to this region. At present, the transfer capital that promotes and promotes domestic is mainly foreign direct investment ${ }^{[6]}$. Since Marshall, the theory of industrial agglomeration has been greatly developed, and the influential ones are: Weber's theory of regional agglomeration, Schumpeter's theory of innovative industrial agglomeration, EM Hoover's theory of optimal scale of industrial agglomeration, Porter's competitive advantage and diamond model, etc. ${ }^{[6]}$.

From the perspective of the characteristics of the "platform model", it is precisely the process of promoting the development of characteristic town based on the characteristic leading industries. Its theoretical cornerstone is the theory of industrial clusters. Essentially, the theory of industrial agglomeration provides a standard theoretical basis and 
scientific explanation for the role of "platform model" characteristic town in promoting regional economy ${ }^{[7]}$.

2) The Theoretical Basis of the "Established Town Model" In 1898, Sir Ebenezer Howard's "Garden City Theory" proposed a structure and spatial model similar to characteristic town. He believes that pastoral cities should not be too large and can provide people with a wealth of social life, entrusted by the commission, the town covers an area of 4.05 square kilometers, living 32000 people, of whom 30,000 are in the city, 2,000 in the countryside ${ }^{[8]}$. Although this kind of planning idea has the idealism color, but "the Garden City theory" is accepted by more and more scholars. The American sociologist Vance proposed the "regional nuclear theory" in 1977. Its main connotations are as follows: the long-distance cities form an independent "core", the population migrates to the suburbs, the suburbs appear the city core, the interaction between the city and the suburbs is reduced; with the emergence of the core of the suburban cities, the suburbs constantly strengthen the city's "self-sustaining ability" and eventually break away from the dependence on the city's central business district to recreate the functions of the new city: entrepreneurship, employment, production, circulation, distribution, consumption and entertainment integration. Vance believes that most urban residents are less likely to use the entire urban area. On the contrary, they live and work in a relatively effective urban space ${ }^{[9]}$. With the market integration of regional economic elements among cities within urban agglomerations, the interaction and convection between cities will inevitably form, which will produce new "growth point" and "node" of economic elements, and then transform into new urban location space. This phenomenon has many special names, such as the city "outer (periphery) town", "micro town", 'technical community" and so on.

"Garden City Theory", 'Regional Core Theory" and "Technological District" provide theoretical support for the development of "town-building model" characteristic town. In the new urbanization construction, characteristic town has become an important carrier for coordinating urban and rural development, and it is also a very effective practice mode, which is an inevitable trend of regional industrial structure optimization and upgrading.

\section{Characteristic Town Development "Dual Mode" CONNECTION}

\section{A. Conceptual Association}

From the concept of "platform model" and "established town model" to the characteristic town, the "platform model" is essentially a new form of block economy, emphasizing the creation of a new platform for innovation-driven development, focusing on the functional concept of "town". The "established town model" is essentially an important practice of the new urbanization. It emphasizes linking the city with the countryside and coordinating urban and rural development. However, the two models are consistent in the extension of concepts, both emphasizing the core extension characteristics of the connotation of "special" supporting characteristic town. The main points are as follows: one is the "special" industry. The characteristic industry is industry or industrial cluster with international, national or local characteristics and core market competitiveness formed with one or several unique resources, culture, technology, management, environment and talent advantages accumulated and shaped by a country or region in the long-term development process ${ }^{[10]}$; the second is the "specialty" of the crowd. The future direction of characteristic town is destined to be a high-end industrial town if it is to become a carrier to enhance the competitiveness of regional and even international industries. Therefore, characteristic town is highly intelligent and highly skilled. The third is the "specialty" of the position; the characteristic town should be at the equilibrium point of the city's agglomeration or decentralization. On the one hand, this area can effectively share the agglomeration economy of the Metropolitan Central area; on the other hand, it can enjoy the quiet living environment of the marginal areas. The fourth is the "specialty" of the function. Macroscopically speaking, the basic function of characteristic town is to promote the structural reform on the supply side. It is an experimental field for County Economic upgrading and a new platform for innovation-driven development.

\section{B. Same Essence}

Different experts have different opinions on the nature of characteristic town. Li Bingdi, deputy director of the Ministry of Housing and Urban-Rural Development and the Economic Development Committee of Small and Medium-sized Cities, believes that 'the core essence of characteristic town is institutional environment. Over the years, superior resources and elements have been highly concentrated in cities, and now we must emphasize the development of livable cities. Yang Guoying, a researcher at China Financial Think Tank, believes that "developing characteristic town is essentially the sinking of the center of urbanization in China". The new-type urbanization advocates the balanced distribution of population and economy in geographical space, and emphasizes the improvement of the anti-magnetic function of small towns. Although it gets rid of the one-sided dependence on small towns in the past, it still emphasizes the important role played by small towns ${ }^{[11]}$. Cai Fang, a member of the Academy of Social Sciences, holds that 'the accumulation of creativity will not lead to industrial dependence and resource depletion. The core lies in the integration of various groups, which is the source of the future total factor productivity. The accumulation of creativity is the essence of urbanization, especially the new urbanization". From the point of view of experts, both "platform model" and "established town model" essentially emphasize the heterotopia of development space, that is, relying on "town" to pool superior resources, reconstruct or define new economic growth point or core of a region.

\section{Same Goal}

The NDRC clearly distinguishes "characteristic town" from "characteristic small towns". The characteristic town proposed by the NDRC is "platform model" and the characteristic town is "established town model". The two models complement each other and support each other. Characteristic town mainly refers to the innovation and entrepreneurship platform which focuses on high-end characteristic industries and collects high-end development elements. It is different from the traditional administrative town and industrial park. Characteristic towns are constructed by traditional administrative divisions, 
distinctive industries and a certain population size and economic basis. Although the two modes have different forms, they are both important platforms for pushing forward the structural reform on the supply side and important graspers for pushing forward the new-type urbanization. Its common purpose is to promote the coordinated development of large, medium and small cities and towns through the transformation of regional development kinetic energy, and give full play to the role of urbanization in radiating and driving the new rural construction.

\section{Functional Convergence}

From the perspective of national policy, "platform model" and "established town model" bear the strategic responsibility of national economic transformation and development, that is, to improve industrial transformation and upgrading, cultivate new economic momentum, and promote new urbanization platform. Macroscopically speaking, the basic function of characteristic town is to promote the structural reform on the supply side. It is the experimental field for County Economic upgrading and a new platform for innovation-driven development. Microscopically speaking, the characteristic town can provide a perfect public service for the enterprises it carries, and provide a comfortable and comfortable ecological environment for the employees. The industrial function, tourism function, cultural function and community function of characteristic town converge with the function orientation of new urbanization in terms of the beautiful environment, livable environment and entrepreneurial atmosphere formed while constructing the industrial ecosphere.

\section{Policy Suggestions and Reflections}

\section{A. Policy Suggestion}

1) Classified guidance and diversified development.

The characteristic town not only embodies the value of optimizing the modern structure of a region's development, but also embodies the Modernity Value of urbanity popularization. At the same time, it also shows that under the premise of global urbanization, it is a new path of development to participate in the global division of labor in the way of characteristic town. The formation of characteristic town is positively related to the level of economic development of the whole society. It is a social development mode under the background of social modernization and post-modern society and also a kind of crystallization of urban life style and "urban civilization popularization rate". Different characteristic town development modes should be chosen in different regions. There are many cities in China, and it is necessary to take the development path of multiple cities and small and medium-sized cities and small towns. However, it should be noted that not all regions in China are suitable for the development of characteristic towns, but should follow the path of categorized guidance, diversification, multi-type and multi-level development.

\section{2) Advance orderly and respect the law.}

"Characteristic town" should be developed naturally under the condition that the local has a certain industrial agglomeration foundation. The construction of characteristic town should respect three laws: the law of economic and social development, the law of urbanization and the law of market economy. The construction of characteristic town is the product of the accumulation of history and culture to a certain extent, the development of characteristic industries to a certain extent, and the development of economy and society to a certain stage. The emergence and continuation of many foreign characteristic towns are not accidental, but naturally formed after decades, even hundreds of years of accumulation and evolution. Therefore, China's cultural town construction can not blindly pursue quick results and quantity, but should highlight the advantages of characteristic industries and take advantage of the trend according to the local unique humanities and geographical environment. In the face of the current construction of characteristic town in full swing, we need to think rationally, see the essence through the phenomenon, and avoid slogan-style and sports-style promotion.

\section{B. Reflections}

1) Plotting for characteristic town is more important than planning

Plotting is the soul of project construction, development, investment and operation, which includes project positioning, industry, humanities, brand, investment and financing, operation, time and space, goal and schedule planning, etc. It is mainly used for answer questions like what kind of town to build, how do you build it, how to build it, who will build it, who will come and so on.

2) The industry of characteristic town is more important than location

Characteristic has only geographical advantages, no unique industrial foundation and industrial clusters, and will be a commercial real estate town after completion. The special industrial foundation and conditions can not only solve the problems of economic development in small towns, but also solve the problems of employment and entrepreneurship. Only industry can gather population, population can form a market, and can drive the daily needs and residential needs of the whole town. The prosperity of a small town must be supported by industry. Without the support of business model, it is difficult to sustain and eventually become an empty city.

3) The method of building characteristic town is more important than capital

Characteristic town is a comprehensive area which covers industries, humanities, science and technology, medical treatment, education, tourism, services, leisure, housing and so on. It requires multi-participation, multi-party linkage, and multi-party integration to form and it is not possible to pile up with money. On the contrary, low cost operation and construction is a favorable weapon to reduce and reduce the risk of characteristic town investment.

4) The survival of characteristic town is more important than policy

The state supports the development of characteristic town by encouraging the government, enterprises and all walks of life in society to pay close attention to and promote the construction of small towns, narrow the gap between urban and rural areas, and promote the integrated development of urban and rural areas in an all-round way. The investment and construction of characteristic town should have enterprise 
thinking, market thinking, commercial thinking and town thinking. We should consider how to make the characteristic town itself have powerful industrial function, market function, commercial function and investment function.

\section{CONCLUSION}

The characteristic town is a new national strategy for urban construction in the new era, aiming at promoting "industrial agglomeration, industrial innovation and industrial upgrading" with "new ideas, new mechanisms and new carriers". In order to seek a new regional development strategy from a higher starting point in a new round, we should actively respond to and implement it throughout the country. Among them, the "platform model" led by Zhejiang economy has achieved ideal results and will continue to develop after the early construction and operation. The "established town model", which is mainly based on administrative divisions, is trying to explore the way of thinking and development. The two modes need both similarities and differences, continuous innovation and context inheritance, as well as coordination and balance. The two modes not only have their own characteristics, but also influence each other, which provide a strong practical basis for the structural reform on the supply side and the realization of the goal of national rural revitalization.

Characteristic town has been rolled out nationwide since 2016. Academic circles have also made a comprehensive analysis and a high degree of generalization on national policy, domestic and foreign theoretical research and so on, and put forward diversified theoretical ideas on town connotation, industry orientation, construction mechanism, development mode, path selection, etc. And specific case studies are carried out in different regions to provide theoretical references and train of thought for the subsequent creation and development of feature town. However, the academic circles have little to do with the evaluation mechanism, assessment rules, long-term planning and so on, which needs further study in the follow-up.

\section{ACKNOWLEDGEMENT}

This paper is one of the phased achievements of the Guangdong Provincial Education Department Study on Characteristic Town Planning from the Perspective of Smart Village-Taking Conghua District of Guangzhou as an Example (2017GWQNCX083).

\section{REFERENCES}

[1] Guo Qin. Path Exploration of the Dual Mode of Sports Characteristic Town Construction[J]. Sports and Science, 2018, 39(3):89-94.

[2] Hao Huayong. Several Relations of Characteristic Town Construction in Underdeveloped Areas [J]. Development Guide, 2017 (6): 70-74.

[3] Zhu Min. The Development Characteristics, Causes and Enlightenment of Zhejiang "Block Economy" [DB/OL]. http://www.sic.gov.cn/News/455/5992.htm, 2016-02-24.

[4] Wang Lijuan. Development Status and Business Opportunities of Characteristic Town in Jiangsu Province [EB/OL].http://3g.163.com/sports/article/D2PTIA3Q9001IA3R.html.

[5] Liang Qian. 2018 China Opens Urbanization Version 3.0 -- The Characteristic Town Will Become An important Carrier [EB/OL]. http://www.xinhuanet.com/2018-01/25/c_129798502.htm.

[6] Chen Yu. Theory and Practice of Urban Renewal (Characteristic Town) [M]. Beijing: China Building Industry Press, 2017: 36-37.

[7] Wei Longbao, Shi Xinjie. Some Thoughts and Suggestions on the Construction of Zhejiang Characteristic Town [J]. Zhejiang Social Sciences, 2016(3): 28-32.

[8] Ebenezer Howard. The Garden City of Tomorrow [M]. Beijing: Commercial Printing House, 2002:11.

[9] James E. Vance. Extended City - Urban Morphology in Western Civilization [M]. Beijing: China Building Industry Press, 2013: 466-467.

[10] [10]Wang Daming. Developing Characteristic Industries is an Effective Way to Accurate Poverty Alleviation in Poor Areas-Taking Guangyuan City in Sichuan as an Example [J]. Journal of Xihua Normal University (Philosophy and Social Sciences), 2017, 1:92-95

[11] Ding Shouhai. Concept Analysis: Urbanization, Urbanization and New Urbanization [N]. Journal of Chinese Social Sciences, 2014-5-30 (A06). 